\title{
Estrategias reproductivas y formación de capital social en contextos migratorios y periurbanos. Un análisis desde la perspectiva de Pierre Bourdieu
}

\author{
José Álvaro Hernández Flores* \\ Susana Rappo**
}

El presente artículo toma como referencia la noción de capital social, desarrollada por Pierre Bourdieu, para examinar el papel que desempeñan las prácticas sociales orientadas a la formación de dicho capital en la conformación de las estrategias reproductivas de los grupos domésticos que habitan en contextos migratorios y periurbanos.

A partir de los estudios de caso expuestos se analizan las principales instancias de acumulación de capital social, sus principios de activación y sus repercusiones sobre los ámbitos familiar y comunitario, así como los cambios acaecidos a partir de los procesos de conurbación y la intensificación del fenómeno migratorio.

Palabras clave: capital social; periurbano; estrategias de reproducción; migración.

Fecha de recepción: 20 de enero de 2015.

Fecha de aceptación: 5 de abril de 2016.

Reproductive strategies and social capital formation in migration and peri-urban contexts. An analysis from the perspective of Pierre Bourdieu

This article draws on the notion of social capital, developed by Pierre Bourdieu, to examine the role of social practices designed to build such capital in shaping the reproductive strategies of domestic groups living in migration and peri-urban contexts.

The case studies described are used to analyze the main forms of accumulating social capital, their principles of activation, and their impact on the family and community spheres, as well as changes that have taken place as a result of the conurbation process and the intensification of the migratory phenomenon.

Key words: social capital; peri-urban; reproductive strategies; migration.

* Catedrático Conacyt, El Colegio de México, Centro de Estudios Demográficos, Urbanos y Ambientales. Dirección postal: Camino al Ajusco 20, Pedregal de Santa Teresa, Tlalpan, C.P. 14200, Ciudad de México, México. Correo electrónico: <jalvaro@ colmex.mx>.

** Profesora investigadora de la Benemérita Universidad Autónoma de Puebla, Facultad de Economía, Centro de Estudios del Desarrollo Económico y Social. Dirección postal: Avenida San Claudio y 22 Sur, s/n, Jardines de San Manuel, C.P. 72570, Puebla, Puebla, México. Correo electrónico:<susanarappo@hotmail.com>. 


\section{Introducción}

En las últimas décadas la noción de capital social ha sido objeto de apropiación por parte de diversos organismos internacionales y agencias de desarrollo, quienes vislumbran en dicho concepto un medio para la reducción de la pobreza y la desigualdad (Durston, 2002); para la cohesión social, la ampliación de oportunidades y el fortalecimiento de la capacidad de agencia de los individuos (PNUD, 2001, 2008); para la movilización de recursos y la construcción de una economía competitiva con sistemas políticos más democráticos y sociedades más solidarias (BID, 2000), y para la promoción de valores éticos y de la cultura cívica (Banco Mundial, 2014), entre otros.

El uso acrítico de este concepto y su elevación al rango de instrumento de política pública por parte de organismos internacionales surge en un contexto de crisis económica e institucional y cuestionamiento generalizado del Estado de bienestar, en el que el capital social se presenta, casi sin reparos, como la solución a todos los males.

La adopción de este tipo de enfoques puede llevar a confundir el potencial explicativo y operativo de dicho concepto con su capacidad real para emprender transformaciones sociales. Asimismo, se corre el riesgo de atribuir a las relaciones sociales la tarea de compensar o de corregir la escasez de oportunidades económicas, resultado de la falta de capital natural o económico, sin considerar que esta relación es mucho más compleja, y que un capital no sustituye, en automático y sin mediaciones, a los otros (Flores y Rello, 2001). Por otro lado, desde la academia, buena parte del debate teórico de los últimos años se ha desarrollado en abstracto, sin referencia a situaciones concretas y locales, o bien referido explícitamente a contextos urbanos, dejando de lado los escenarios rurales o periurbanos que por su propia naturaleza parecerían los más idóneos para analizar el concepto de capital social (Durston, 2002).

Lo anterior obliga a revisar el concepto de capital social, asumiendo posturas o enfoques críticos que problematicen dicha noción, destacando no sólo sus potencialidades, sino sus lados oscuros, así como los efectos sociales y políticos de su apropiación y uso.

A partir del análisis de dos estudios de caso -ubicados en dos localidades periurbanas de origen rural, aledañas a la capital del estado de Puebla, en la región centro de México-, el artículo indaga en torno a los procesos de formación de capital social en contextos afectados por el proceso migratorio, así como el papel que desempeñan dichos 
procesos en la conformación de las estrategias de reproducción social de los grupos domésticos. Para ello se retoma el enfoque teórico de Pierre Bourdieu, quien postula un concepto de capital social problemático que hace explícito el papel ambiguo que desempeñan las relaciones sociales en los procesos de desarrollo de las sociedades.

La elección de las localidades de estudio se fundamentó en tres criterios definidos a partir de los objetivos de la investigación, así como de los requerimientos de orden analítico que demanda la elaboración de un trabajo bajo la perspectiva teórica de Bourdieu:

a) Localidades cuyo proceso de periurbanización estuviera fincado sobre la base de una población con antecedentes rurales, a modo de analizar el papel de las prácticas agrícolas y el modo de vida rural en la formación de capital social.

b) Localidades con sistemas de estrategias de reproducción social distintas, en donde las prácticas agrícolas y migratorias estuvieran siempre presentes.

c) Proximidad física entre ambas localidades a modo de poder comparar con mayor precisión las diferencias existentes en la configuración de las estructuras objetivas externas, y las incorporadas bajo la forma de habitus.

En este sentido el municipio de San Pedro Cholula se configuró como un escenario ideal para el estudio, no sólo por el papel que ha desempeñado la agricultura en la región desde tiempos prehispánicos, sino por la importancia que tienen en su vida cotidiana las actividades rituales tradicionales y las instituciones informales asociadas a ellas -en particular el sistema de cargos-, aspectos que han llevado a considerar a Cholula como "un caso único, una situación extrema para la que resulta difícil encontrar paralelo en los estudios sobre los ámbitos sociales contemporáneos" (Bonfil, 1973: 117).

Durante el primer semestre de 2008 se llevaron a cabo 20 entrevistas a profundidad a jefes y jefas de familia de grupos domésticos que habitan en ambas localidades. La selección de la población entrevistada se llevó a cabo a partir de un muestreo de tipo intencional en el que la determinación de las unidades de muestreo se orientó por el criterio de saturación teórica (Ruiz, 1999).

Para la interpretación de los datos se privilegió una aproximación de tipo cualitativo -que incluyó como principales técnicas de recolección y análisis de resultados la observación participante, la entrevista 
a profundidad y el análisis de contenido-, la cual permitió caracterizar las estrategias de reproducción social de los grupos domésticos, al tiempo de profundizar en la comprensión de los mecanismos involucrados en la producción de prácticas sociales y productivas de dichos grupos, en particular aquellas asociadas a la periurbanización y al fenómeno migratorio.

\section{El capital social desde la perspectiva de Bourdieu}

Las primeras formulaciones del concepto de capital social se remontan a la década de los ochenta, a partir de los trabajos clásicos de Bourdieu (1986), Coleman (1990) y Putnam (1993), quienes se consideran los autores fundacionales.

Con base en estos primeros trabajos se destacan dos tipos de definiciones. Por un lado, están las que apelan al actor (también llamadas egocéntricas), representadas por las posturas de Bourdieu y Coleman, para quienes el capital social constituye un recurso individual que se deduce de las relaciones sociales, y que se extrae y moviliza en función de los intereses del actor. Y por otro lado, están las definiciones orientadas al sistema (también llamadas sociocéntricas), las cuales conciben al capital social como un atributo colectivo que si bien puede redituar en beneficios individuales, sus efectos más visibles son de orden macrosocial. Este tipo de definiciones, sustentadas a partir de los trabajos de Putnam, han sido retomadas ampliamente por autores de diferentes disciplinas académicas, así como por diversos organismos y agencias internacionales de desarrollo. En buena medida, la aceptación de dicha formulación se deriva de la carga valorativa del concepto de capital social, que asume bajo dicha postura una connotación positiva que oculta, entre otras cosas, su carácter asimétrico y sus conexiones con procesos más amplios vinculados con la dinámica de las clases sociales y el poder (Ramírez, 2005).

La propuesta de Bourdieu que se retoma en este trabajo considera al capital social como "el conjunto de recursos actuales o potenciales, ligados con la posesión de una red duradera de relaciones más o menos institucionalizadas de interconocimiento e interreconocimiento, o en otros términos, con la pertenencia a un grupo como conjunto de agentes no solamente dotados de propiedades comunes, sino también unidos por lazos permanentes y útiles" (Chauviré y Fontaine, 2008: 21). Esta categoría incluye todo el conjunto de contactos, relaciones, 
conocimientos, amistades, obligaciones (deudas simbólicas), que un agente social incorpora a lo largo de su trayectoria y que lo dota de un poder de acción o reacción más o menos importante, en función de la calidad y cantidad de sus conexiones con el resto de los agentes.

La importancia del capital social, de acuerdo con Bourdieu, radica en que se juega en todos los campos sociales sin ser exclusivo de ninguno, y que al vincular el capital económico o cultural propio con el del resto de los agentes con los cuales está relacionado, se configura, por un efecto de agregación simbólica, como una suerte de potencia, como si las riquezas materiales y simbólicas de los agentes de connivencia se adicionaran virtualmente. De esta manera, al examinar a profundidad los beneficios económicos de las distintas formas de intercambio social y su rendimiento diferencial según las distintas clases y grupos sociales, Bourdieu ilumina un fenómeno bastante usual, pero cuyas causas permanecen ocultas en el resto de las formulaciones: el hecho de que diferentes individuos obtengan rendimientos desiguales a partir de un capital cultural o económico equivalente (Marrero, 2006).

Una de las principales aportaciones de Bourdieu, no sólo al concepto de capital social, sino a la teoría de la reproducción, es el análisis de las denominadas "estrategias de reconversión", entendidas como el conjunto de prácticas en virtud de las cuales los individuos, para apropiarse de los beneficios derivados de la apropiación del capital, convierten o transforman en múltiples momentos de su trayectoria un tipo de capital en otro (por ejemplo, capital económico en capital social que posteriormente será reconvertido en capital económico o de otra especie); lo que dado el mecanismo de simulación del carácter económico de buena parte de la vida social, contribuye a la legitimación de dicha apropiación.

Las conclusiones que se desprenden de este tipo de análisis problematizan y cuestionan las premisas de las que parte el discurso dominante sobre el capital social. En palabras de Marrero (2006: 84): "Si el capital es fungible, y cada transformación de una forma de capital en otra conlleva además un costo, no es fácil ver cómo partiendo de situaciones de pobreza o de miseria, podría llegarse, por la simple dinámica de las transformaciones de capital, a superar esas condiciones de privación”. De esta manera, desde el enfoque de Bourdieu el capital social asume un carácter neutro y ambivalente, mucho más acorde con las limitaciones estructurales y los márgenes de maniobra que afrontan los agentes sociales en su vida cotidiana, que con las potencialidades que se le atribuyen como instrumento de política pública. 
Para los fines de este trabajo se retoma la noción de capital social que propone Bourdieu, así como sus principales categorías analíticas. Con ello se busca analizar el papel que desempeña la formación de capital social como parte de las estrategias de reproducción que emprenden los grupos domésticos que habitan en contextos territoriales marcados por la periurbanización y el fenómeno migratorio.

\section{Dos localidades rurales atrapadas entre la migración y el crecimiento urbano}

San Francisco Coapa y San Gregorio Zacapechpan son dos localidades periurbanas, ubicadas en el municipio de San Pedro Cholula, aledaño a la ciudad capital de Puebla. Más allá de su contigüidad física, estas dos localidades comparten características comunes derivadas principalmente de su condición periurbana, del arraigo de las prácticas agrícolas, así como de la incidencia del fenómeno migratorio.

Pese al crecimiento de la mancha urbana y a la paulatina penetración de prácticas culturales asociadas al modo de vida urbano, resulta notable el predominio en ambas localidades de prácticas sociales y productivas que remiten a lo rural. En el caso de San Gregorio Zacapechpan predomina la agricultura de riego orientada al cultivo de hortalizas y otros productos comercializables; en tanto que en San Francisco Coapa, ante la escasez de pozos, se practica una agricultura de temporal con fines de autoconsumo. De ahí que la primera muestre un perfil ocupacional más cargado hacia el sector primario (72\% de la población ocupada), en tanto que en la segunda este porcentaje es considerablemente menor (34 por ciento).

La preponderancia de las actividades agropecuarias queda en evidencia al analizar las categorías bajo las cuales los pobladores de ambas localidades se insertan al mercado de trabajo, en donde las actividades que se desarrollan por cuenta propia (44.9\% en San Gregorio y $48.5 \%$ en San Francisco), o las que se desempeñan bajo la modalidad de jornalero o peón (29.5 y 41.2\%), representan en su conjunto 74.4 y $89.7 \%$, respectivamente, porcentajes que superan por mucho al resto de la población que se ocupa como empleado u obrero en las zonas urbanas aledañas. Asimismo, el carácter familiar e informal de las labores agrícolas se puede apreciar en el porcentaje de la población ocupada que no recibe ingreso por su trabajo (23.9 y $17.6 \%$, respectivamente); en quienes reciben menos de un salario 
mínimo mensual (28.6 y 30.8\%); así como en el alto porcentaje de población (96.4 y 99.7\%) sin derechohabiencia a los servicios de salud (INEGI, 2000, 2005b).

La crisis agrícola que aqueja al país desde los años ochenta, aunada a las cada vez mayores dificultades para satisfacer las necesidades familiares únicamente a partir de las actividades agrícolas, propiciaron que desde hace varias décadas los habitantes de estas localidades -sobre todo los que se ubican en tierras de temporal y producen, por tanto, para el autoconsumo- optaran por la migración transnacional como una vía para asegurar la reproducción familiar. Las tasas de crecimiento promedio anual (TCPA) ${ }^{1}$ muestran el grado de intensidad con que el fenómeno migratorio se ha hecho presente. Y es que mientras en la cabecera municipal de San Pedro Cholula la TCPA de la población registrada en el decenio 1990-2000 fue de 2.82\%, en San Francisco Coapa se registró una tasa de crecimiento negativa del orden de $-0.85 \%$ y en San Gregorio Zacapechpan de $-1.23 \%$, configurándose como las dos localidades del Área Metropolitana Puebla-Tlaxcala (AMPT) que más población expulsaron durante ese decenio (INEGI, 2005b). Más aún, durante el decenio 2000-2010, esta tasa decreció en San Francisco Coapa a un ritmo galopante de $-3.1 \%$, mientras que en San Gregorio Zacapechpan hubo una modesta recuperación del orden de $1.63 \%$. Así, tras varias décadas de crecimiento poblacional sostenido, la población total registrada en 2010 en San Francisco Coapa (2 637 habitantes) es casi la misma que tenía esta localidad a mediados de los años ochenta, y en San Gregorio Zacapechpan (6 959 habitantes) es apenas ligeramente superior que la consignada veinte años atrás, en el censo de 1990. Lo anterior nos puede dar una idea de la magnitud con que se presenta el fenómeno migratorio en estas dos localidades, pese a que el flujo migratorio internacional se ha reducido notablemente en los últimos años como resultado del endurecimiento de las políticas migratorias en los Estados Unidos y de la crisis económica que afecta a dicho país.

Como veremos a continuación, la migración y las prácticas agrícolas, que constituyen los ejes que articulan las estrategias de reproducción en ambas localidades, imponen ciertos requerimientos en términos de

1 La TCPA indica el número de personas en que aumenta o disminuye cada año la población por cada 100 habitantes. Este indicador resume los efectos sobre la población de los tres fenómenos demográficos: fecundidad, mortalidad y migración. Dado que las dos primeras variables tienden a mantenerse estables, este indicador se utiliza para analizar la intensidad de la migración. 
organización y uso de recursos, los cuales inciden en el desarrollo de estrategias de inversión social orientadas a la formación de capital social familiar y comunitario. En el siguiente apartado se analizará la forma en que la acumulación de esta modalidad de capital contribuye a la reproducción de los grupos domésticos, al mismo tiempo que impone restricciones y delimita fronteras identitarias en un territorio marcado por la disputa entre los modos de vida rural y urbano.

\section{Estrategias orientadas a la acumulación de capital social familiar}

En las localidades de estudio, al igual que en otras áreas rurales, la familia es uno de los componentes del capital social que aparece como común denominador de todas las relaciones y acciones de los pobladores. En efecto, la literatura antropológica consigna a las redes de parentesco -expandidas en el espacio y sumadas a otras redes de pertenencia sociocultural y/o territorial- como recursos fundamentales para la satisfacción de necesidades básicas de los grupos domésticos, en particular entre las clases más empobrecidas.

Las redes de parentesco, en tanto ámbito de relaciones institucionalizadas y estables, constituyen la primera instancia de formación de capital social de los grupos domésticos. Cabe señalar que este tipo de redes excede el ámbito espacial de la unidad residencial, es decir, se refiere a una red de contactos y relaciones mucho más extensa y sutil que la que se limita al círculo del hogar. De esta manera, cuando hablamos de redes de parentesco nos referimos no sólo a la denominada "familia de residencia", la cual se caracteriza por la cohabitación de sus integrantes en un mismo espacio, sino a la "familia de interacción”, la cual incluye a parientes que viven en diferentes hogares pero que se encuentran ligados íntimamente por interacciones u obligaciones recíprocas.

En el caso de San Francisco Coapa y San Gregorio Zacapechpan las redes de parentesco cumplen con funciones que se derivan tanto de las condiciones precarias bajo las cuales se lleva a cabo la reproducción, como de la intensidad con la cual se presenta el fenómeno migratorio.

A partir de las entrevistas a profundidad realizadas en ambas localidades fue posible constatar la presencia de numerosas familias nucleares con un patrón de residencia independiente. Este hecho con- 
trasta con la conformación familiar dominante en la mayor parte de las localidades rurales del municipio de San Pedro Cholula, donde la corresidencia intergeneracional que tiene lugar bajo un patrón de residencia de carácter patrivirilocal suele ser la norma.

En una primera aproximación puede resultar paradójico que la configuración de los grupos domésticos en estas localidades sea preponderantemente nuclear, pese a los factores de índole socioeconómica que actualmente juegan contra esta forma de organización familiar. En teoría, en condiciones de precariedad, frente a las prolongadas ausencias de los miembros del grupo doméstico, y ante la tarea de mantener cultivados los terrenos agrícolas, parecería que una configuración familiar compuesta o extensa podría representar una solución adecuada para subsanar el déficit de fuerza de trabajo y asegurar el apoyo, cooperación y solidaridad que garantizan la subsistencia del grupo doméstico. Sin embargo, en las localidades de estudio esto no sucede así. La razón principal detrás de esta peculiaridad radica en el papel que desde hace algunos años desempeña la migración como práctica alrededor de la cual se articulan el resto de las estrategias de reproducción familiar. La acumulación de capital económico que esta actividad supone permite a los grupos domésticos de reciente formación acumular en un plazo muy corto el suficiente capital económico para independizarse de sus localidades de origen y emprender una estrategia de neolocalidad.

Antes casi la mayoría no se apartaban de sus papás, siempre vivían en la misma casa y ahora ya no, porque ahora ya se juntan, tienen un niño y luego ya quieren para hacer su casita, ya casi vivir independientemente de los papás [Natividad, 23 años, San Gregorio Zacapechpan].

Esta observación es compartida por Ariza y Oliveira (2001), quienes sostienen que por su fuerte tendencia a la fragmentación de los espacios residenciales, la migración internacional contribuye de manera directa a la pérdida de importancia de la corresidencia como criterio de pertenencia a los grupos domésticos. La afirmación es aplicable al caso de las localidades de estudio, en donde es casi imposible encontrar un grupo doméstico completo, ya que todas las familias tienen a uno o más de sus integrantes trabajando en Estados Unidos. De esta manera, como resultado de la transmutación social que implica el paso de campesino a migrante y de migrante a campesino, los grupos domésticos de estas localidades periurbanas transitan perma- 
nentemente -tanto en el origen como en el destino- de unificados a dispersos y de éstos a aquéllos.

La presencia marginal que guarda la estrategia de corresidencia generacional no implica en modo alguno que las relaciones de parentesco y consanguinidad no constituyan objeto de interés por parte de los agentes sociales. Por el contrario, frente a las condiciones sociales y económicas que implica la migración, las estrategias de inversión social referidas al ámbito familiar revisten especial importancia.

En las localidades de estudio las redes que se construyen alrededor de las "familias de interacción" desempeñan un importante papel, tanto en el intercambio de información y la movilización de recursos que hacen posible la migración, como en el desarrollo de actividades productivas que demandan el uso intensivo de fuerza de trabajo, en contextos donde ésta constituye un recurso escaso.

Las redes de migración, entendidas como "conjuntos de relaciones interpersonales que vinculan a los migrantes o a los migrantes retornados con los parientes, amigos o compatriotas que permanecen en el país de origen" (Massey, citado por Arango, 2000: 41) encuentran en las familias de interacción una de sus principales instancias de formación. En este tipo de redes, el capital social que se ha generado en virtud de lazos afectivos y de las deudas simbólicas que se adquieren en los grupos domésticos se moviliza con la intención de brindar al migrante la información necesaria para emprender el viaje, sufragar los costos del mismo, y facilitar tanto el proceso de integración al mercado laboral en los lugares de destino, como la adaptación del migrante a sus nuevas condiciones de vida.

Mi hermano el más chico fue el que me mandó a llamar: mira que esto, que lo otro, que hay chamba por aquí. Y sí, llegué allá con chamba [...] nomás me habló y me dijo: tú vente para acá, nosotros te echamos la mano. Que me lleva con su patrona y le dice: Mira, él es mi hermano. Y luego luego entré con ellos [José Isabel Teles, 47 años, San Francisco Coapa].

Allá se recomienda uno en el trabajo, si conoces a alguien de por allá te recomienda. Van y le dicen al patrón: mira ése es mi hermano y te dan permiso [Francisco Alonso, 41 años, San Francisco Coapa].

Como se aprecia en los testimonios, las redes de parentesco resultan fundamentales para el sostenimiento y desarrollo de las prácticas migratorias que tienen lugar en esta localidad. A partir de ellas 
los migrantes consiguen insertarse con relativo éxito en el mercado de trabajo, reconvirtiendo el capital social acumulado a nivel comunitario y familiar en capital económico que regresa a la localidad de origen vía las remesas. Estos recursos contribuyen de manera importante a la reproducción social de los grupos domésticos que permanecen en la localidad. Asimismo, ayudan a financiar la manutención de los migrantes retirados, quienes en su momento emprendieron el viaje a Estados Unidos y canalizaron recursos al grupo doméstico desde el extranjero. En este último caso, la red de parentesco funciona como mecanismo que permite la conversión de capital económico en capital social que al paso de los años será reconvertido nuevamente en capital económico.

Yo ya no [regreso a Estados Unidos] porque ya están allá mis hijos. Yo tengo el apoyo de ellos y por eso ya no pienso irme. Si no tuviera el apoyo de ellos pues a lo mejor sí me iba, pero como tengo el apoyo ya no es necesario que yo vaya; entonces así estamos: ellos por allá, y yo por acá, y así estamos unidos [Eusebio Ramírez, 52 años, San Francisco Coapa].

Las redes de parentesco proporcionan a los migrantes una estructura de apoyo que les permite hacer frente a los problemas derivados de su falta de presencia en el hogar-sobre todo en lo relacionado con el cuidado de los niños y adultos mayores que se quedan en la localidad-, así como mantener el control sobre áreas específicas que son de su interés o que se encuentran fuertemente arraigadas en el habitus ${ }^{2}$ local, como son la vigilancia de la propiedad rural y la realización de labores agropecuarias que por su propia naturaleza no permiten postergación.

De esta manera, el interés de la población migrante por mantener bajo cultivo permanente los terrenos agrícolas, incluso en los casos en que la mayor parte del grupo doméstico ya no vive en la localidad, sólo puede realizarse a partir de las redes de parentesco extensas. Ante la ausencia del jefe de familia o de algunos de sus integrantes, esta red cumple un papel relevante aportando de manera solidaria fuerza de

2 Bourdieu (1991: 88-89) define a los habitus de modo general como los condicionamientos asociados a una clase particular de condiciones de existencia. Señala que son "sistemas de disposiciones duraderas y transponibles, estructuras estructuradas predispuestas a funcionar como estructuras estructurantes, es decir, en tanto que principios generadores y organizadores de prácticas y representaciones que pueden estar objetivamente adaptadas a su fin sin suponer la búsqueda consciente de fines y el dominio expreso de las operaciones necesarias para conseguirlos". 
trabajo adicional que permite cubrir la cuota mínima requerida para el desarrollo de las actividades agrícolas; o en el caso de que todo el grupo doméstico haya emigrado, custodiando los terrenos de la familia que está ausente.

La gente da los terrenos para que, pues si está aquí un familiar de ellos, los trabajen. Les dicen: No, pues allá trabájalo y ya lo que tú saques es para ti. Mucha gente no quiere que su terreno esté parado, como es temporal te dicen: No, pues allá trabájalo [Jacinto Teles, 36 años, San Francisco Coapa].

Esos [terrenos] los cultivan algunos familiares. Por ejemplo, el papá de la familia de mi esposa, se fue toda la familia y dejaron todo el terreno a cargo de su hermano. Ahí siembra nopalitos o lo que tenga. O también lo renta. Algunos los dejan empeñados, a cinco o a seis años, pero los dejan más que nada con sus familiares [Juan Cielo, 36 años, San Gregorio Zacapechpan].

En el caso de los grupos domésticos cuya familia de interacción es limitada o inexistente, o que por circunstancias diversas no pueden echar mano de ella, existen prácticas como el "encargo" o la "mediería", las cuales permiten que agentes sociales con terreno, pero sin suficiente fuerza laboral, entren en contacto con agentes que carecen de terrenos, pero que cuentan con fuerza laboral en abundancia; todo esto bajo un esquema de colaboración informal que supone beneficios para ambas partes.

Hay algunos, si no hijos, nietos; si no nietos, damas, que no pueden ir a Estados Unidos [...] ¿a qué se dedican?, pues piden terrenos a medias. Se dan cuenta que alguien no puede trabajar y le dicen: Oye, dame tu terreno. Pues sí, trabájalo. Y lo trabajan por la misma necesidad de ellos mismos; así los terrenos casi no se dejan de trabajar, uno se va acomodando dándolos a medias [Teodoro Pérez, 73 años, San Gregorio Zacapechpan].

Aquí se quedan los papás o los familiares a cargo de las tierras, les mandan el dinero para que trabajen las tierras y no queden abandonadas $[\ldots]$ es como ahora, yo me voy pero dejo los terrenos a una familia para que me los trabaje, y nos vamos a medias [Antonia Alonso, 36 años, San Francisco Coapa]. 
De esta forma, el capital social invertido en el fortalecimiento y consolidación de los vínculos que integran la red de parentesco permite al migrante mantener sus terrenos en cultivo permanente, al tiempo que los grupos domésticos locales cuentan con un medio de subsistencia o con una fuente adicional de ingresos.

Yo tengo mi familia también allá, y les digo: No pues mándame algo para los terrenos para cultivarlos, mándame unos 100 dólares. Y ellos me dan de 200 a 300 dólares y ya se cultivan sus terrenos. Los cultivamos y ese dinero se le mete al terreno y ya después que sale la cosecha pues si uno lo vende, pues ya tiene un poco de dinero [Francisco Alonso, 41 años, San Francisco Coapa].

La solidaridad familiar en forma de prestaciones, ayuda mutua, apoyos brindados y recibidos entre miembros de una misma familia que habitan en grupos domésticos distintos, y en general las formas de solidaridad que trascienden los ámbitos espaciales del hogar, constituyen un recurso relevante en contextos caracterizados por la marginación, la incertidumbre y la inestabilidad. En este sentido, tener o no muchos hijos, sobrinos o nietos, suele ser un factor que, frente a ciertas estructuras sociales externas, puede significar el éxito o el fracaso de las estrategias de reproducción que emprenden los grupos domésticos.

En este punto conviene retomar a Bourdieu (2002), quien afirma que de todas las estrategias de inversión biológica, quizá las más importantes son las denominadas estrategias de fecundidad. Éstas, concebidas a muy largo plazo, comprometen todo el futuro de la descendencia y del patrimonio, y tienen por objeto controlar el número de hijos y, por tanto, la fuerza del grupo familiar; aunque también el número de pretendientes potenciales al patrimonio material y simbólico heredado. Bourdieu señala que según el estado de los medios disponibles, este tipo de estrategia puede tomar caminos directos, como el control natal, o indirectos, como el matrimonio tardío o el celibato. ${ }^{3}$

Algunos de los testimonios que se recogieron durante el trabajo de campo aludieron a las altas tasas de fecundidad que predominan

3 Bourdieu (2002) señala que éste es el caso de la orientación hacia el sacerdocio de algunos hijos en las familias aristocráticas o la imposición del celibato a los hijos menores en algunas sociedades campesinas, con la intención de favorecer al primogénito. 
en las localidades de estudio ${ }^{4}$ como una estrategia adoptada por los agentes sociales de manera consciente y dirigida con la intención de cubrir los requerimientos de fuerza de trabajo que suponen las labores agrícolas. Esta fuerza de trabajo, debido a que forma parte de una unidad de producción imbricada orgánicamente con una unidad de consumo, no es remunerada económicamente en los mismos términos en que lo hace el mercado, lo cual representa una ventaja para el grupo doméstico.

[Tenemos] tantos hijos porque vas al campo, llevas a todos tus hijos y lo desenyerbas y lo abonas de volada. Aquí la familia así ha sido. Es como ahorita mi sobrino ya tiene tres [hijos] y se me hace que ya va para otro. Aquí en el pueblo así es. Tienen de a quince, de a diez [...] la familia tiene que entrar a ayudarnos al campo porque pues uno solito, derecho que no [se puede]. Se pueden buscar chalanes, pero pues queda el dinero para los peones $[\ldots]$ entonces, de que le pague yo al peón, pues mejor le pago a mis hijos; bueno, no les pago, pero ya comen, ya viven ahí, ya tienen su casita más o menos, porque si no, todo el peón se lo lleva [Eduardo Juan, 51 años, San Gregorio Zacapechpan].

Algunos testimonios vincularon la iniciación temprana a la vida conyugal, y por tanto, a la maternidad o la paternidad, con las expectativas de bienestar a largo plazo, situación que permitiría encuadrar a dichas prácticas como parte de las denominadas estrategias de inversión biológica orientadas a asegurar la manutención económica y los cuidados continuos de la salud de los cónyuges en la vejez, a partir del control de la fecundidad, y por tanto, de la administración del patrimonio y de las deudas simbólicas y afectivas inculcadas a los descendientes (Bourdieu, 2002).

Pues yo me junté de 16 años y ya tengo 21 años de casada [...] aquí la mayoría se casa de 18. Es mucha edad [casarse] de 18. De 20 o 25 es muy difícil, y ya de 30 no, ya se quedan [...] si no voy a tener un hijo al rato ya me enfermé y quién me cuida, nadie. Ahorita yo tengo mis hijos, si algún día ya no puedo trabajar, ya me enfermé, ya ellos vendrán a de-

4 Según el INEGI (2010) el promedio de hijos nacidos vivos en San Gregorio Zacapechpan es de 2.95 y en San Francisco Coapa de 3.14 contra 1.98 de la capital poblana, 3.04 de las localidades rurales del estado y 2.27 de las localidades urbanas. Este indicador resulta de dividir el total de hijos nacidos vivos de las mujeres de 12 años y más, entre el total de mujeres de ese grupo de edad, por lo cual es un mero indicativo, ya que no muestra el promedio real de hijos que tienen las mujeres al final de su ciclo biológico reproductivo. 
cirme: mamá la voy a cuidar [Antonina Alonso, 36 años, San Francisco Coapa].

Si bien se carece de elementos suficientes para relacionar estas disposiciones socioculturales con las condiciones objetivas bajo las cuales se lleva a cabo la reproducción, sí es posible afirmar que, desde la perspectiva de los entrevistados, una familia numerosa incrementa las posibilidades no sólo de llevar a buen término la empresa agrícola, sino de asegurar una vejez sin preocupaciones económicas. El siguiente testimonio muestra de manera muy clara cómo la procreación es vislumbrada como una inversión en capital social a largo plazo; una apuesta que puede salir bien o mal, pero que en el contexto de precariedad, incertidumbre laboral y ausencia de un andamiaje institucional que garantice la seguridad social y el sostén económico de los adultos mayores, acrecienta la probabilidad de envejecer dignamente.

Me dicen unos amigos: Tú trabajaste harto para los hijos. Fueron siete hombres y dos mujeres, nueve en total. ¿Se imagina?, zapatos, ropa, escuela, comer, bañarlos. Pues le eché hartas ganas; inclusive ¿¿sabe qué le decía a mi esposa? éstas son mis alcancías, a éstos les estoy dando ahorita, cuídamelos, porque cuando lleguen a ser grandes, nomás me conformo de 50 pesos que me den, son siete, son 350 pesos a la semana y ya con eso me la paso. Entonces fueron mis alcancías donde yo trabajé y deposité mucho. Lo bueno es que me salieron buenos, me aprecian, y tampoco me dan mucho, pero tampoco me dan poquito [Feliciano, 67 años, San Gregorio Zacapechpan].

Si bien como se ha señalado en este apartado, el capital social familiar constituye un importante recurso para la reproducción social en contextos migratorios, los lazos de colaboración y cohesión que existen dentro de las redes de parentesco no son, en modo alguno, de naturaleza idílica. Por el contrario, se trata de vínculos asimétricos y ambivalentes donde la solidaridad suele estar acompañada por el conflicto y/o la subordinación.

En efecto, la confluencia de relaciones de parentesco, residencia y producción en el seno del grupo doméstico, así como la vinculación de las actividades de producción y consumo que ocurren en su interior, suelen ocultar las aportaciones y las cargas de trabajo que asumen de forma individual algunos integrantes del grupo doméstico, las cuales se diluyen en un monto determinado de capital social familiar. Tal es el caso del trabajo productivo -en el predio o fuera de él- que asumen 
las mujeres ante la ausencia prolongada del cónyuge y de los hijos o hermanos varones. Estas tareas se suman a las ya de por sí pesadas e invisibilizadas actividades de índole reproductiva, vinculadas principalmente a la organización del hogar, la crianza de los hijos y el cuidado de los ancianos, lo que supone el desarrollo de dobles, o inclusive triples jornadas, cuyas aportaciones, por lo regular, no son visualizadas y mucho menos valoradas por los agentes sociales.

\section{Estrategias orientadas a la acumulación de capital social comunitario}

La noción de comunidad constituye un referente ineludible de las localidades de estudio. Es en el interior de la misma donde podemos constatar la existencia de innumerables vínculos que se construyen en diferentes niveles que abarcan desde el ámbito de lo familiar hasta los más amplios escenarios de los ritos y las festividades religiosas colectivas, pasando por un conjunto de expresiones sociales en el ámbito de lo microsocial que tienen que ver con las formas de organización de los grupos domésticos, las relaciones entre los habitantes y los patrones de la relación colectiva propios de la vida cotidiana (Grajales y Concheiro, 2008).

La interrelación de los campesinos con sus iguales en el marco de la comunidad constituye una de las instancias de formación de capital social más recurridas en los ámbitos rurales. Los vínculos comunitarios, producto de un largo devenir histórico, confieren a la comunidad una fuerte identidad cultural, la cual se configura como un principio productor de prácticas sociales orientadas a la conformación de redes de relaciones y de alianzas entre grupos domésticos afines, que reducen la incertidumbre frente a las condiciones externas. Dichas redes están vertebradas por la confianza, atributo que surge a partir del contacto directo y permanente entre agentes que ocupan posiciones similares en el espacio social, y que por tanto comparten ciertas propiedades comunes. Esto no quiere decir que a nivel comunitario no se presenten rupturas, divisiones, conflictos, e incluso enfrentamientos entre los distintos grupos sociales; sino que frente a lo extraño, lo externo o lo ajeno es posible distinguir cierta homogeneidad cultural, una defensa interna y casi cohesión ante la cual los sectores externos y la comunidad misma son permanentemente modificados (León, 2000).

En el caso de las localidades periurbanas que han sido trastocadas de modo severo por el crecimiento de la ciudad y la penetración de los 
procesos urbanos, las redes comunitarias basadas en relaciones de parentesco, de vecindad y de camaradería, tienden a reducir el sentimiento de incertidumbre e inseguridad frente a procesos y actores externos.

En las localidades de estudio la seguridad constituye una de las principales funciones que cumple esta red de relaciones comunitarias, la cual, en ciertos momentos coyunturales, ante la presencia de amenazas externas, es capaz de transmitir información con gran rapidez y desplegar una poderosa respuesta colectiva.

En San Francisco Coapa, por ejemplo, existe el antecedente no muy remoto de un linchamiento comunitario al que se vieron sometidos un par de vendedores de libros que para su desgracia fueron confundidos por los habitantes de la localidad con "robachicos" (Shadow y Rodríguez, 1991). Asimismo, hace un par de años, en el contexto de una disputa con el gobierno estatal por la construcción de una carretera, los habitantes de esta misma localidad retuvieron a varios ingenieros de la Secretaría de Comunicaciones y Transportes (SCT) que realizaban trabajos de medición sin permiso, los cuales fueron liberados horas después tras la negociación con las autoridades estatales (Diario Intolerancia, 2009).

El testimonio que se presenta a continuación ilustra la forma en que se estructura a nivel comunitario la respuesta ante cualquier amenaza, real o potencial, de índole externa.

Acá, por ejemplo, cuando hay un robo, hay que ir a hablar con el presidente y es el que da el aviso a todos los comandantes. Hay que ir a traer al mayordomo con el portero de la iglesia, se tocan las campanas y se junta la gente. No, pues que hay un robo, ¿̇de quién?, de fulano. La otra vez se juntaron como 100 personas y salieron a buscarlos [Don Silviano, 66 años, San Francisco Coapa].

Las redes que se construyen con base en capital social comunitario cumplen también importantes funciones de sostén social, que van desde el intercambio de información, apoyo moral, solidaridad y ayuda mutua, aspectos de suma importancia en contextos migratorios y periurbanos, sometidos a transformaciones profundas que ponen en riesgo la reproducción.

La formación de capital social comunitario no se puede desvincular de la noción de reciprocidad, entendida como el principio fundamental que rige las relaciones formales e informales en una comunidad, el cual se basa en una relación permanente y continua de intercambio que 
aunque puede no ser equivalente en un momento dado, mantiene la expectativa de beneficios mutuos y equiparables en el largo plazo. En una situación donde los ejercicios de reciprocidad se repiten con frecuencia -como sucede en la mayoría de las sociedades rurales- el capital social tiende a incrementarse en virtud de las deudas simbólicas que ligan a los agentes, favoreciendo la cooperación, la solidaridad, la ayuda mutua.

Los testimonios recopilados a lo largo del trabajo de campo confirman que esta labor de construcción y mantenimiento de las redes sociales forma parte de las prácticas cotidianas que despliegan los grupos domésticos.

Ejemplo de lo anterior es la costumbre del "convite" que tiene lugar cuando se realiza una fiesta, el cual consiste en una aportación, ya sea en especie o en trabajo, que se hace de manera voluntaria a los organizadores de la misma, quedando éstos obligados a corresponder de la misma manera. Por lo regular este tipo de intercambio de favores se despliega durante la celebración de acontecimientos como los bautizos, los quince años, las bodas y los funerales. Esta práctica, fundamentada en la reciprocidad, permite que el capital social acumulado a lo largo de los años por un agente pueda ser movilizado al mismo tiempo, de manera conjunta, para aligerar tanto la carga de trabajo como los costos económicos que implica la organización de un festejo. En este sentido, el "convite" constituye una forma no monetaria de acceder a mano de obra y otros recursos para llevar a cabo una actividad social que de otra manera sería irrealizable. Para los agentes sociales de San Gregorio Zacapechpan, dar o pedir "prestado" se considera una inversión de la que tarde o temprano se obtendrá algún tipo de beneficio material o simbólico.

Uno siempre ayuda con una bolsa de azúcar, una bolsa de sal, una maleta de pescado, picante para el mole, todo lo da "prestado" y ya cuando llega el mero día [que a uno le toca festejar] se lo devuelven de nuevo [...] siempre parejo nos convidamos, así es la tradición aquí [Luciano Ramírez, 40 años, San Francisco Coapa].

Mi mamá me hizo la boda, se hizo en grande, hubo grupo y todo, pero al otro día pues sí, levantarse desvelado, bien cansado y a lavar todos los trastes y todo y empezar a pagar lo que se pidió prestado. Porque aquí en una fiesta tenemos la costumbre de que voy a ver al vecino: no pues préstame una caja de botellas, préstame tres guajolotes, préstame un marrano, entonces ya después de la fiesta ya nos empiezan a cobrar: No, pues que es el santo de mi esposo y quiero mi caja de botellas. Entonces hay que 
trabajar más para empezar a pagar todo lo que se disfrutó en una noche [Delfino Cielo, 34 años, San Gregorio Zacapechpan].

El capital social es un poder que exige inversiones permanentes en tiempo, esfuerzo, en otros capitales, y puede aumentar o disminuir, mejorando o empeorando las posibilidades de quien lo posea. Se fundamenta, pues, en lazos permanentes y útiles que se sostienen en intercambios que son a la vez materiales y simbólicos (Gutiérrez, 2003). El padrinazgo y el compadrazgo son dos ejemplos de instituciones ligadas una con otra, muy arraigadas en la región de Cholula, las cuales se construyen a partir de este tipo de intercambios que se dan entre agentes que, en virtud de la posición que ocupan en el espacio social, presentan una fuerte similitud u homología.

El compadrazgo es una forma de parentesco ritual que se establece en torno a los más diversos acontecimientos de la vida. Es un nexo familiar-espiritual permanente que implica obligaciones recíprocas y conducta ritual cuando la ocasión lo requiere (Bonfil, 1973). En este sentido, es una institución que se define en el marco de relaciones de reciprocidad simétricas que buscan ampliar la red de contactos y desarrollar relaciones largas y duraderas. Por su parte, el padrinazgo articula por lo regular redes asimétricas de intercambio, ya que el capital social de un agente (el ahijado) es tanto más efectivo cuanto mayor sea el poder relativo y la posesión de recursos económicos del otro agente (el padrino) con el cual se relaciona.

Para que este tipo de prestaciones funcione se requiere que el perfil de los grupos domésticos, en términos de la distribución y volumen de las diferentes especies de capital, presente una fuerte similitud u homología. De ahí que las redes tengan sus límites espaciales bien definidos y que instituciones como el compadrazgo o el padrinazgo, las cuales implican derechos y obligaciones bien definidos, sólo puedan ocurrir entre agentes sociales que comparten un mismo territorio y por tanto una misma matriz cultural y social.

[Como padrino] se gasta reharto, se gastan mínimo unos cincuenta o sesenta [mil pesos], por eso a muchos de los que viven afuera [de la comunidad] los van a ver para padrinos y no quieren, dicen que no porque es muy caro [Natividad Ramírez, 55 años, San Francisco Coapa].

En las localidades de estudio, donde la migración ha introducido diferencias económicas notables entre los agentes sociales, las inver- 
siones en capital social que se dan vía el padrinazgo se han encarecido a lo largo de los últimos años, sobre todo para los agentes que permanecen en la localidad, quienes se ven obligados a competir con sus pares que trabajan en Estados Unidos. Esta situación ha derivado en presiones de muy diversa índole para los grupos domésticos locales, quienes, o bien se ven excluidos de estas instancias de formación de capital social, o se integran a ellas a un costo económico sumamente alto.

Por ejemplo, va a salir mi hijo [de la escuela] y le busco un padrino. No, pues busco a un fulano que sé que está en Estados Unidos [...] al estar en Estados Unidos, en lugar de darle su bicicleta de mil pesos, a lo mejor le compra una televisión grande, inclusive una moto; entonces, cuando vienen a ver a un padrino de acá y [éste] llega con su bicicleta, pues como que ya se siente mal [...] por ejemplo, ahora si me vienen a ver como padrino, cómo voy a irme a meterme a la escuela nomás con un ramito pequeñito, o qué se yo, nada más una cajita de regalo. No, pues de a mínimo su bicicleta, entonces pues sí, la gente que está allá como que nos obliga a gastar más [...] Una fiesta de un casamiento es igual, a veces ponen el pique: no pues que mi compadre de pastel está en los Estados Unidos; el de brindis está en Estados Unidos; el de recuerdos es de acá; el de florado es de acá; entonces imagínese para competir con los de allá. A veces hasta pedimos prestado dinero. Si el padrino de allá va a traer lo mejor, pues yo voy a tratar de traer algo mejor, entonces a veces gastamos lo que no tenemos, eso es lo que los de allá nos presionan [Delfino Cielo, 34 años, San Gregorio Zacapechpan].

Mi hijo, el mayor, cuando se vino a casar fuimos a ver a su padrino de bautizo. El padrino tiene que dar desayuno en su casa, tiene que poner la música, tiene que poner el equipo para la novia. Sí está muy pesado. Entonces me decía mi compadre: No, pues discúlpeme compadre, pero no puedo. Y yo le decía: No compadre, usted acepte sin compromiso, quiero que lo acompañe. No, pero la gente qué va a decir. No, pero de la gente no nos vamos a fijar, esto es entre nosotros, esto es un acuerdo. No pues que sí. Y sí, lo comprometí con un dinerito más o menos [Don Silviano, 66 años, San Francisco Coapa].

Sin negar las ventajas y los beneficios que la acumulación de capital social representa para los agentes sociales de esta localidad, es necesario agregar que en muchas ocasiones, dado que lo que se busca es la vinculación con personas de mayor disponibilidad de capital global, las relaciones que resultan de estos intercambios se inscriben en una 
situación de subordinación, e incluso de dependencia, tal como lo expresa el siguiente testimonio:

Mi padrino es buena onda en cuestión de que regala, pero a veces cuando lo voy a visitar quiere que tome yo a fuerzas y me obliga. ¿Y cómo me obliga? Me dice que yo tengo la obligación de a fuerzas de convivir con él. Yo a veces le he explicado que la convivencia no es siempre la del licor, sino la de venir a platicar, pero él a lo mejor lo toma de otra manera. O sea, a veces voy por la calle y se me olvida saludarlo; no, pues ya se enoja y me reclama: No, que yo ya gasté tanto y tú ni siquiera me hablas [Delfino Cielo, 34 años, San Gregorio Zacapechpan].

En este sentido, se puede postular que esta modalidad de intercambio supone reciprocidades que compensan la desposesión de una especie particular de capital, con la que el otro agente posee. Cabe agregar que en muchas ocasiones este tipo de vínculos suelen involucrar no sólo a los individuos, sino a los grupos domésticos completos, llegando incluso a ligar a dos generaciones diferentes en un sistema de dones y contradones, diferidos a lo largo del tiempo, sustentados en la acumulación de capital social doméstico.

Además de los sistemas de reciprocidad mencionados anteriormente, existen otro tipo de instituciones que se despliegan a nivel comunitario y que se configuran como instancias productoras de capital social. Tal es el caso de la “cooperación comunitaria”, práctica sumamente extendida a lo largo del territorio cholulteca, la cual supone la aportación regular de recursos monetarios por parte de los habitantes de la localidad para financiar festividades religiosas y civiles.

Aquí coopera toda la comunidad. Todas las festividades, fiestas que hay, ponen una cooperación; entonces los fiscales bajan a hacer la recolección cada ocho días, cada quince días [...] el que no se ha casado no tiene que cooperar, pero si se casa ya lo anotan, hay un padrón general [Silviano, 66 años, San Francisco Coapa].

[Aquí] hay las cooperaciones, una pasadita, o lo que sea, aquí todos tenemos que cooperar, aquí es por ley que tenemos por cooperar [Antonina Alonso, 36 años, San Francisco Coapa].

El incumplimiento de la cooperación tiene fuertes sanciones tanto en el terreno civil como en el religioso. Supone la exclusión del grupo doméstico de la vida social y comunitaria, y por tanto, la renun- 
cia a los beneficios derivados de la pertenencia a la red de relaciones que se establece a nivel comunitario. Quien no paga la cooperación no puede asistir a las fiestas, ni solicitar servicios religiosos o civiles. Vaya, ni siquiera puede ser enterrado en el panteón de la localidad. De ahí que los grupos domésticos hagan extraordinarios esfuerzos por cumplir con ella.

Es tan fuerte la coerción social hacia el cumplimiento de esta institución, que incluso quienes residen en Estados Unidos envían regularmente dinero destinado a cumplir con sus obligaciones comunitarias. Para los migrantes la cooperación constituye una forma de refrendar su pertenencia a la red comunitaria, y por tanto, de mantener vigentes los derechos que están asociados a la misma. La participación de los ausentes en la vida comunitaria permite afianzar su identidad individual y colectiva, así como mantener vivos los vínculos sociales y afectivos en su lugar de origen ante la posibilidad de un eventual retorno.

Dada la gran cantidad de migrantes que hay en esta localidad, el flujo de recursos que se destina a las obras comunitarias ha aumentado en los últimos años de manera considerable. Esto ha permitido a los habitantes de San Francisco Coapa incursionar en la construcción de obras de gran envergadura que anteriormente eran impensables. El ejemplo más plausible de esta situación lo encontramos en la edificación del nuevo templo, un edificio de dimensiones exageradas, construido con materiales de la más alta calidad, el cual fue financiado exclusivamente a partir de las cooperaciones comunitarias.

\footnotetext{
Ahorita ya van gastados más de cuatro millones de pesos en la iglesia [...] [los de afuera] nos mandan sus centavos y acá tenemos las comisiones [...] Por ejemplo, 150 personas ponen y nos cooperamos de a 1500 pesos para la iglesia, y así va saliendo todo. Ahorita pusieron el piso que costó como 500 mil pesos, es de mármol [...] entre todo el pueblo lo juntamos [Francisco Alonso, 41 años, San Francisco Coapa].
}

El flujo creciente de remesas hacia ambas localidades se ha traducido en un incremento tanto en los montos como en la frecuencia de las cooperaciones comunitarias, aumentando la presión económica sobre los grupos domésticos locales, quienes se ven en serias dificultades para cubrir la cuota que exige el cumplimiento de sus compromisos comunitarios. Ante la imposibilidad de sustraerse de esta contribución "voluntaria", algunos habitantes se han visto obligados a migrar, 
dando lugar a una paradoja evidente, ya que para poder seguir siendo reconocidos como miembros de la comunidad, tienen que salir expulsados de ella.

El motivo por el que a veces ya no quiere uno vivir por acá es por las cooperaciones del pueblo [...] como ahorita que se está haciendo el trabajo del templo se está cooperando desde mil; luego viene la fiesta, ésa viene de a cien, de a doscientos [...] a veces nos toca la cooperación de dos mil, tres mil, y aunque no quiera uno tiene que poner [...] Se endroga uno. Ahora que se está haciendo este trabajo del templo piense que si la gente no estuviera en el otro lado no se hiciera ese trabajo. Ahorita nuestras familias nos mandan el dinero y ya cooperamos; pero ¡vaya!, es dura aquí la cooperación. Todo el año es puro dinero, puro dinero [Félix Vázquez, 60 años, San Francisco Coapa].

No me alcanza el dinero y eso que no vivimos una vida de ricos. Tenemos más o menos para ir comiendo, lo que pasa es que también aquí en el pueblo hay muchas cooperaciones [...] todo el año redondo es estar detrás de la cooperación: si no es la escuela, es lo de la iglesia, si no es la iglesia, es lo de la presidencia, o sea que siempre estamos ahí y no alcanza. Entonces a veces de desesperación sí piensa uno: mejor me voy a Estados Unidos otra vez [Delfino Cielo, 34 años, San Gregorio Zacapechpan].

La mayoría se van al norte, ya no quieren seguir en el campo porque no deja mucho y los gastos son caritos aquí en el pueblo. Las tradiciones más que nada son las que nos hacen gastar, las cooperaciones de la iglesia, de las esquinas, misas y todo eso. Las personas que ya se juntaron tienen que cooperar y luego viene el bebé, y son gastos que se hacen, y luego aquí ya entrándole a la cooperación, pues mejor se van [Natividad, 23 años, San Gregorio Zacapechpan].

Pese a lo anterior, los agentes sociales siguen cumpliendo con la cooperación comunitaria. La persistencia de esta institución nos habla, por un lado, de la eficacia con que operan los mecanismos de control social que tienden a homogeneizar las prácticas sociales entre los agentes, al tiempo que denota también las ventajas que comporta la pertenencia a las redes sociales comunitarias, aunque como veremos más adelante, tanto en San Francisco Coapa como en San Gregorio Zacapechpan -localidades muy afectadas por el fenómeno migratorio- esta institución social ha comenzado a ser cuestionada por algunos migrantes.

Otro de los aspectos que la migración ha trastocado de manera importante es la organización social tradicional que durante siglos ha 
predominado en el territorio cholulteca, en particular en la localidad de San Francisco Coapa. ${ }^{5}$ En esta localidad mestiza de origen indígena, donde la administración de la vida civil descansa en una serie de cargos voluntarios elegidos bajo el sistema de usos y costumbres, se ha empezado a registrar un proceso de reconfiguración sociodemográfica que pone en entredicho la viabilidad de estas formas organizativas comunitarias. La expulsión poblacional, en particular la de los varones en edad productiva, ha generado vacíos que ante la inminente partida a Estados Unidos poca gente está dispuesta a cubrir. El testimonio del presidente auxiliar de San Francisco Coapa es elocuente en este sentido:

Año tras año se dificulta encontrar gente [...] Por usos y costumbres [se nombra] también al cuerpo de Policía. Son voluntarios, no perciben ningún sueldo, y también la gente pues ya no quiere [...] la gente ya sale nombrada y dice que no puede que porque a los quince días o al mes ya se va. Dicen: Yo no quiero responder que sí y vas a ver que el día de mañana ya no estoy $[\ldots]$ desafortunadamente, como usted verá, nosotros estamos solos, no tengo ningún regidor, unos se fueron para Estados Unidos [...] aquí en las juntas auxiliares no percibimos ningún sueldo, es por eso que la gente opta por irse a los Estados Unidos [Jacinto Teles, 36 años, San Francisco Coapa].

A decir de las autoridades civiles no sólo el trabajo y el servicio comunitario están en decadencia. También las cooperaciones extraordinarias destinadas a mejorar la infraestructura de los servicios en la localidad. A diferencia de lo que sucede con la "cooperación comunitaria" en donde la población migrante contribuye de manera importante para financiar la construcción del templo, la fiesta patronal y otras festividades religiosas, en el caso de las cooperaciones que se solicitan para introducir servicios públicos o mejorar la infraestructura la respuesta de los migrantes es prácticamente nula. Al no estar sancionadas socialmente, y por tanto, no garantizar ni en el corto ni en el largo plazo una tasa de conversión favorable al capital económico invertido, estas cuotas extraordinarias sólo son cubiertas por la población local, lo que en muchos casos limita la construcción de obras públicas que son necesarias y relevantes.

San Francisco Coapa es la única junta auxiliar de San Pedro Cholula que todavía mantiene el cargo de topil (mensajero, cartero), entre otros cargos tradicionales que son elegidos por la vía de los usos y costumbres. 
Hernández Flores y Rappo, ESTRATEGIAS REPRODUCTIVAS

Los que están aquí pues cooperan, pero los que no están no cooperan, o sea, unas obras no se pueden realizar si no estamos todos unidos. Nos faltaron dos calles por cumplir del drenaje, aproximadamente en esa calle los beneficiados eran 50 personas y de esas 50 personas únicamente le estaban entrando 15 que son las que están aquí en la comunidad, la mayoría está en Estados Unidos. Les hablaron sus familiares y les dijeron: Yo no lo necesito ahorita, no estoy ahí. Bueno, pero siquiera manda tu cooperación. No, dicen, ahí háganle como quieran. Entonces se está perdiendo esa costumbre de cooperar [... yo hice una convocatoria una vez, queríamos tener todo alumbrado [...] mandé a la gente de Estados Unidos que colabore, que dé su cooperación. Yo les dije: No les voy a pedir mucho, nomás de a 500 dólares, ¿cuántas familias hay allá?, les dije, el dinero se va a manejar bien [...] pero la gente no cooperó, mucha gente me decía: No, para qué si yo no estoy ahí [Jacinto Teles, 36 años].

Como se puede apreciar, la migración ha tenido efectos tanto positivos como negativos en el campo de las relaciones sociales. Dichas transformaciones han modificado de manera profunda las estrategias de inversión social, orientando las apuestas de los agentes sociales hacia la producción de prácticas que les permitan acreditar su pertenencia a la comunidad, y por tanto, mantener vigentes los derechos que les corresponden en virtud de dicha adscripción. Sin embargo, queda por ver hasta qué punto el fenómeno migratorio -y la expulsión poblacional que éste implica- permite la continuidad de las formas internas de organización a nivel local, o en su defecto, cuál será la magnitud de los cambios en la dinámica comunitaria como resultado de la adaptación a las nuevas condiciones sociodemográficas.

\section{Migración y capital social, una relación problemática}

En las localidades periurbanas objeto de este trabajo, las estrategias orientadas a la acumulación de capital social han cobrado importancia a partir de la intensificación del fenómeno migratorio.

Los aportes a la reproducción por parte del conjunto de prácticas que se despliegan para producir, acumular y reconvertir el capital social son evidentes cuando se analizan, por ejemplo, las funciones que desempeñan las redes a nivel familiar y comunitario en relación con el proceso migratorio, en el que aspectos básicos como la planeación del viaje, el contacto con el pollero, el pago del traslado, los gastos de vivienda y, sobre todo, la integración al mercado laboral de la Unión 
Americana forman parte de los beneficios y ventajas que ofrece la pertenencia a estos tipos de red.

El caso de los migrantes es muy ilustrativo ya que permite observar con claridad cómo opera la reconversión de capital social en capital económico. También permite constatar cómo el volumen de capital social de un agente en particular depende no sólo de la extensión de la red de relaciones que él puede efectivamente movilizar en un momento determinado, sino también del volumen de capital económico o cultural o simbólico de cada uno de los agentes a los cuales está ligado por la pertenencia a esa red.

No obstante, el capital social posee también un "lado oscuro" cuyos efectos no son tan evidentes, y que en contextos migratorios pueden llegar a verse acentuados (Portes, 1998; Portes y Landolt, 1996). Tal es el caso de la invisibilización y no valoración de las aportaciones individuales a la reproducción familiar por parte de las mujeres que se quedan a cargo de los grupos domésticos ante la ausencia del jefe de familia o los hijos varones.

Asimismo, cabe señalar otros aspectos negativos vinculados al funcionamiento eficaz del capital social comunitario, tales como los procesos de exclusión social que se derivan del establecimiento de límites que definen quiénes tienen derecho a beneficiarse de la red de relaciones y quiénes no, así como las restricciones a las libertades individuales que se expresan en los mecanismos de control social que sancionan el incumplimiento o la no participación dentro de las instancias formadoras de capital social comunitario.

En contextos migratorios, donde los grupos domésticos están fragmentados y existe un importante flujo de remesas, algunas instituciones formadoras de capital social, como la cooperación comunitaria, los padrinazgos y los compadrazgos, pueden llegar a convertirse en una pesada carga para los integrantes que permanecen arraigados en la localidad, muchos de los cuales, con tal de refrendar su pertenencia a la comunidad, se verán obligados a migrar.

Frente a este tipo de repercusiones conviene recuperar la propuesta de Portes (1998), quien llama a mantener presentes los diversos efectos negativos del capital social para esquivar la tentación tautológica de inferir la existencia de capital social únicamente a partir de la presencia de sus efectos positivos. 
Hernández Flores y Rappo, ESTRATEGIAS REPRODUCTIVAS

\section{Conclusiones}

A lo largo de las últimas décadas, San Francisco Coapa y San Gregorio Zacapechpan han experimentado con particular intensidad la penetración del modo de vida urbano y el surgimiento de fenómenos emergentes como la migración. En este contexto plagado de incertidumbre, las redes -familiares y comunitarias- cobran particular relevancia, funcionando, por un lado, como estructura que resguarda y da certidumbre a los grupos domésticos que la integran, al tiempo que permiten delimitar fronteras y generar respuestas frente a las acciones de agentes sociales pertenecientes a otros ámbitos, que son percibidas como una amenaza.

Las redes de parentesco no sólo desempeñan un importante papel en el intercambio de información y la movilización de recursos que hacen posible la migración, sino que además permiten mantener vigente la producción agrícola local y generar oportunidades de empleo a nivel local, pese a la salida constante de población.

Por su parte, la red de relaciones que tiene como referente a la comunidad campesina, además de cumplir con las funciones de seguridad, apoyo moral, solidaridad y ayuda mutua -de gran importancia en contextos migratorios-, permite la realización de actividades que las familias son incapaces de ejecutar de manera individual, o que por separado resultan económicamente inviables. Adicionalmente, dada la periurbanización acelerada que experimentan estas localidades, constituye también una forma de defensa frente al asedio de actores externos.

La existencia de prácticas instituidas a nivel local, regional, e incluso internacional, para crear, reforzar, mantener, acompañar y reactivar los vínculos de la red de relaciones comunitarias, sugiere el interés estratégico por parte de los grupos domésticos por refrendar su membresía y acceder eventualmente a los beneficios de índole social, económica o simbólica derivados de su pertenencia.

No obstante, como lo constatan los testimonios referidos a las instancias de formación de capital social comunitario, estas redes no deben mitificarse, ya que por lo general están integradas por relaciones llenas de ambivalencia, que en algunos contextos y en ciertas circunstancias pueden ser vividas por los agentes sociales como una imposición, carga u obligación moral que no siempre se puede cumplir y cuya transgresión suele venir acompañada de un costo social muy alto. 
La adopción de una noción problemática de capital social que visibilice los efectos perniciosos, ambivalentes y asimétricos asociados a la conformación de las distintas redes de relaciones, pudiera ser, en este sentido, una vía propicia para el análisis de contextos sometidos a profundos cambios y transformaciones, como los que tienen lugar en las localidades periurbanas de estudio.

Una visión crítica sobre el capital social podría contribuir, por ejemplo, a examinar con mayor detenimiento la relación entre la intensidad del fenómeno migratorio y el incremento de las cargas y obligaciones vinculadas a la pertenencia a una red. También podría ser útil para validar o descartar el sentido estratégico de las prácticas de fecundidad y corresidencia, así como para analizar las modalidades bajo las cuales dichas prácticas se integran al sistema de estrategias de reproducción familiar. La perspectiva de Pierre Bourdieu que se asume en este trabajo puede ser de gran utilidad al respecto.

\section{Bibliografía}

Arango, Joaquín (2000), "Enfoques conceptuales y teóricos para explicar la migración", Revista Internacional de Ciencias Sociales, núm. 165, pp. 33-47. Disponible en: <www.unesco.org/new/fileadmin/MULTIMEDIA/HQ/ SHS/pdf/165-fulltextspa165.pdf> (10 de diciembre de 2014).

Ariza, Marina y Orlandina de Oliveira (2001), "Familias en transición y marcos conceptuales en redefinición", Papeles de Población, núm. 28, pp. 9-39. Disponible en: <www.redalyc.org/pdf/112/11202802.pdf > (13 de noviembre de 2014).

Banco Mundial (2014) What is Social Capital?, Washington, Banco Mundial < http://go.worldbank.org/VEN7OUW280> (13 de marzo de 2014).

BID (2000), Marco estratégico para la participación ciudadana en las actividades del Banco Interamericano de Desarrollo, Washington, Bando Interamericano de Desarrollo <http:/ / www.iadb.org/etica/iniciativa.cfm $>$ (13 de septiembre de 2011).

Bonfil, Guillermo (1973), Cholula, la ciudad sagrada en la era industrial, Puebla, BUAP.

Bourdieu, Pierre (1986), "The forms of capital", en J.G. Richardson (coord.), Handbook of Theory and Research for the Sociology of Education, Nueva York, Greenwood Press.

Bourdieu, Pierre (1991), El sentido práctico, Madrid, Taurus.

Bourdieu, Pierre (2002), "Estrategias de reproducción y modos de dominación”, Colección Pedagógica Universitaria, núm. 37-38, pp. 1-21. 
Chauviré, Christiane y Olivier Fontaine (2008), El vocabulario de Bourdieu, Buenos Aires, Atuel.

Coleman, James (1990), Foundations of Social Theory, Cambridge, Harvard University Press.

Diario Intolerancia (2009), "Habitantes de Coapa retienen a ingenieros de la SCT; se oponen al despojo de tierras”, Diario Intolerancia, Puebla, México, 18 de agosto.

Durston, John (2002), El capital social campesino en la gestión del desarrollo rural. Díadas, equipos, puentes y escaleras, Santiago de Chile, CEPAL.

Flores, Margarita y Fernando Rello (2001), "Capital social: virtudes y limitaciones", ponencia presentada en la Conferencia Regional sobre Capital Social y Pobreza, CEPAL / Universidad de Michigan, Santiago de Chile, 24 a 26 de septiembre de 2001.

Grajales, Sergio y Luciano Concheiro (2008), "San Salvador Atenco: un territorio en disputa. De la defensa de la tierra a las nuevas territorialidades", ponencia presentada en el seminario internacional Las configuraciones de los Territorios Rurales en el Siglo XXI, Pontificia Universidad Javeriana, Bogotá, 24 a 28 de marzo.

Gutiérrez, Alicia (1997), Pierre Bourdieu. Las prácticas sociales, Córdoba, Argentina, Universidad Nacional de Córdoba / Universidad Nacional de Misiones.

Gutiérrez, Alicia (2003), "La construcción social de la pobreza. Un análisis desde las categorías de Pierre Bourdieu", Revista Andaluza de Ciencias Sociales, núm. 2, pp. 29-44.

INEGI (1990), Censo General de Población y Vivienda, informe particular, México, ITER, Instituto Nacional de Estadística y Geografía.

INEGI (2000), Censo General de Población y Vivienda, informe particular, México, ITER, Instituto Nacional de Estadística y Geografía.

INEGI (2005a), II Conteo de Población y Vivienda, 2005, México, ITER, Instituto Nacional de Estadística y Geografía.

INEGI (2005b), La migración en Puebla, México, Instituto Nacional de Estadística y Geografía.

INEGI (2010), Censo General de Población y Vivienda, informe particular, México, ITER, Instituto Nacional de Estadística y Geografía.

León, Arturo (2000) "Una propuesta para investigar las estrategias de reproducción campesina en Tierra Caliente, Guerrero”, en Roberto Diego Quintana (coord.), Investigación social rural. Buscando huellas en la arena, México, UAM / Plaza y Valdés, pp. 105-120.

Marrero, Adriana (2006), "La teoría del capital social, una crítica en perspectiva latinoamericana”, Arxius de Sociología, núm. 14, pp. 73-89. Disponible en: <https:/ / dialnet.unirioja.es/servlet/articulo?codigo $=2254036>$ (13 de enero de 2016).

PNUD (2001), Desarrollo humano en Chile 2000. Más sociedad para gobernar el 
futuro, Santiago de Chile, Programa de las Naciones Unidas para el Desarrollo.

PNUD (2008), Informe sobre desarrollo humano. Michoacán 2007, México, Programa de las Naciones Unidas para el Desarrollo.

Portes, Alejandro (1998), "Social capital: its origins and applications in modern sociology”, Annual Review of Sociology, vol. 24, núm. 1, pp. 1-24. Disponible en: <http://www.annualreviews.org/doi/pdf/10.1146/annurev. soc.24.1.1> (15 de enero de 2015).

Portes, Alejandro y Patricia Landolt (1996), "The downside of social capital", The American Prospect, vol. 7, núm. 26, pp. 18-21. Disponible en: <https:// www.questia.com/magazine/1G1-21093810/the-downside-of-social-capital> (15 de enero de 2015).

Putnam, Robert (1993), Making Democracy Work: Civic Traditions in Modern Italy, Princeton, Princeton University Press.

Ramírez, Jorge (2005), "Tres visiones sobre el capital social: Bourdieu, Coleman y Putnam”, Acta Republicana. Política y Sociedad, año 4, núm. 4, pp. 21-36. Disponible en: <http://www.tribunaeducacio.cat/wp-content/ uploads/2016/02/3-visiones-CS1.pdf> (14 de noviembre de 2014).

Ruiz Olabuenaga, José Ignacio (1999), Metodología de la investigación cualitativa, Bilbao, Universidad de Deusto.

Shadow, Robert y María de J. Rodríguez (1991) "Los robachicos. San Francisco Coapa, Puebla”, México Indígena, núm. 23.

\section{Acerca de los autores}

José Álvaro Hernández Flores es doctor en Ciencias con especialidad en Estrategias para el Desarrollo Agrícola Regional por el Colegio de Postgraduados y licenciado en Economía por la Universidad Nacional Autónoma de México. Es miembro del Sistema Nacional de Investigadores, nivel I. Ha desarrollado estancias de investigación en el Instituto Gino Germani de la Universidad de Buenos Aires y en el Centro de Estudios del Desarrollo Económico y Social (CEDES) de la Benemérita Universidad Autónoma de Puebla. Actualmente se encuentra adscrito como catedrático Conacyt al Centro de Estudios Demográficos, Urbanos y Ambientales de El Colegio de México. Entre sus principales líneas de investigación destacan: desarrollo sustentable, estrategias de reproducción social, y configuración de los territorios rurales y periurbanos. 
Susana Edith Rappo Miguez es egresada de la Universidad Nacional Autónoma de México y de la Universidad Nacional de Rosario, Argentina. Es doctora en Economía por la UNAM. Desde 1980 es profesora investigadora en la Facultad de Economía de la Benemérita Universidad Autónoma de Puebla; en dicha institución también es miembro del Centro de Estudios del Desarrollo Económico y Social (CEDES) y del Cuerpo Académico "El desarrollo del capitalismo contemporáneo: actores sociales y construcción de opciones de vida en el mundo rural". Imparte clases y asesora tesis de licenciatura, maestría y doctorado, y realiza diversas actividades de gestión académica. Sus líneas principales de investigación se ubican en aspectos agrarios, de desarrollo rural y sustentabilidad, así como en aspectos socioterritoriales y de actores sociales. 
